\title{
Presentación Dosier
}

\section{Carlos Rincón LECTOR, CRÍTICO, FABULADOR}

E1 24 de diciembre de 2018 falleció Carlos Rincón en Berlín. Unas horas después, muchos de los que en algún momento compartimos con él nos enteramos de ese inesperado hecho por algún obituario marginal en el periódico o en la página de alguna de las instituciones en las que construyó su itinerario intelectual. El fallecimiento del crítico cultural, maestro, gestor cultural y traductor resonó como el eco de una piedra que cae en un profundo pozo... luego se fue apagando lentamente. Casi seis meses después, un grupo de alumnos del profesor Rincón y yo nos reunimos para hablar de ese silencio y de las preguntas que nos suscitaba su enorme, fragmentada e inconclusa obra. Reflexionábamos sobre el olvido deliberado de la academia colombiana frente a su obra; sobre lo incómodo de su pensamiento para las instituciones encargadas de la construcción de la memoria en el país; sobre sus afinidades con ciertos autores, entre ellos Hans Blumemberg, Guilles Deleuze, Walter Benjamin y Jorge Luis Borges; sobre el trato particular que tenía con sus estudiantes; sobre la aventura que significaba emprender un proyecto editorial con él; sobre su papel en la crítica latinoamericana a lo largo de más de 50 años; y sobre su visión de la recepción de la estética y la filosofía en la Universidad Nacional de Colombia.

Fruto de esas conversaciones, surgió el deseo de hacer un homenaje a su obra y a su trabajo. Inicialmente, y gracias al apoyo de los Departamentos de Literatura y de Filosofía de la Universidad Nacional de Colombia, dicho homenaje se realizaría en una jornada completa el 31 de octubre de 2019 en el auditorio Margarita González del edificio de Posgrados de Ciencias Humanas. Sin embargo, el evento no fue ajeno a las contingencias del país: el 31 de octubre la Universidad Nacional se estaba preparando para el paro nacional convocado para el 21 de noviembre; por esta razón, el ambiente, además de académico, era el de las asambleas estudantiles, la movilización y los bloqueos de edificios. A eso de las dos de la tarde, y debido a las protestas, el evento debió suspenderse. En esta primera jornada participaron Alejandro Sánchez Lopera, 
coeditor y gestor de este proyecto; Pablo Valdivia, exalumno de Carlos y profesor de la Universidad de Viadrina; Cristian Moreno, filósofo y exalumno de la Universidad Nacional; Jonathan Beltrán, editor de Sombralarga; y, por último, Jorge Mario Múnera, uno de los fotógrafos más importantes de la historia colombiana contemporánea - cuyas fotografías usa Rincón en uno de sus libros- La segunda jornada se realizó con el apoyo del Instituto Caro y Cuervo en el auditorio Ignacio Chaves el 19 de noviembre. Este día, a pesar de una lluvia torrencial, nos reunimos toda una tarde para continuar escudriñando la obra de Carlos Rincón. Allí participaron Víctor Viviescas, dramaturgo y profesor del Departamento de Literatura de la Universidad Nacional; Sarah González de Mojica, profesora retirada de la Universidad Javeriana, compañera de aventuras intelectuales de Rincón; Constanza Toquica, directora del Museo Colonial; y, por último, Paola Montero, coeditora y coautora de Fealdad gracia y libertinaje. Estética y modernidad en el pensamiento colombiano (2018). Este dosier es, de alguna manera, la continuación y expansión de las reflexiones leídas en esas dos jornadas. Es nuestra contribución para preservar el legado intelectual que dejó Carlos Rincón.

Para el lector no iniciado, quizá valga la pena nombrar algunos hechos relevantes de su fascinante biografía. Carlos Rincón nació en Bogotá en 1937. Se doctoró en Leipzig (antigua RDA) en 1965 con una disertación sobre el teatro de García Lorca bajo la dirección de Werner Krauss, reconocido académico alemán que fue condenado a muerte y cuya pena fue conmutada por el régimen nazi por cargos de alta traición, y de Werner Bahner, otro reconocido romanista. Durante su estancia en Alemania fue apadrinado por Elisabeth Hauptmann, colaboradora de Bertolt Brecht y miembro del Berlin Ensambler. Entre 1965 y 1981 contribuyó con traducciones para la mítica revista ECO de autores como Walter Benjamin, Theodor Adorno, Mijail Bajtín, Jürgen Habermas, Jean-François Lyotard, entre otros. Durante los años ochenta fue consejero de Ernesto Cardenal, importante teólogo de la liberación que en aquel entonces era el Ministro de Cultura del gobierno creado por el Frente Sandinista de Liberación Nacional en Nicaragua. Durante toda su carrera participó en los comités editoriales de revistas como Crítica Literaria Latinoamericana del Centro de Estudios Cornejo Polar (Lima/Berkeley), Travesía. Journal of Latin American Studies (Londres) y Estudios de Literatura Colombiana (Universidad de Antioquia). Entre sus publicaciones en español se destacan El cambio en la noción de literatura (1978), La no-simultaneidad de lo simultáneo (1995), Mapas y pliegues. Ensayo de cartografía cultural y de lectura del neobarroco (1996), Garcia Márquez, Hawthor- 
ne, Shakespeare, de la Vega E Co. Unltd (1999), Avatares de la memoria cultural en Colombia. Formas simbólicas del Estado, museos y canon literario (2010) e Íconos y mitos culturales en la invención de la nación en Colombia. En sus últimos años editó la obra crítica de Hernando Téllez y Hernando Valencia Goelkel, así como la obra del filósofo Francisco Posada.

El lector de este dosier se dará cuenta de que la obra de Carlos Rincón atraviesa casi medio siglo de historia de la teoría crítica y cultural mundial y latinoamericana. En sus obras se anudan el marxismo, el postestructuralismo, la teoría postmoderna, la teoría de la recepción, los estudios literarios, los estudios culturales y los estudios poscoloniales de una forma original y subversiva. Los textos incluidos en este dosier abordan problemas transversales a su trabajo intelectual: la (i)legibilidad, las artes de la lectura, las condiciones que posibilitan regímenes de interpretación, la memoria cultural, la crítica a las instituciones, el lugar de la cultura latinoamericana en el sistema global, la escritura como forma de abordar la complejidad, entre otros. Aparece aquí el Rincón hermeneuta; el autor polémico que inquiere por los sinsentidos y los lapsus; el pragmatista que afronta la multiplicidad; el ácido crítico de momentos lúcidos y de sinsalidas; el estratega que dejó esbozos, preguntas por proseguir, mapas por poblar. El hacedor de mundos y plegables, de origami, dibujante de rutas por dónde "adelantar los debates".

Para finalizar, quisiéramos agradecer particularmente a Gerda Schattenberg, viuda de Carlos, quien se mantuvo al tanto de lo que hacíamos en Bogotá, y que con generosidad nos ofreció material inédito para el dosier —el boceto de abstract del último proyecto de investigación de Rincón, así como el texto con las palabras que leyó Karlheinz “Carlo” Barck en 2003 en el Instituto Latinoamericano de la Freie Universität de Berlín, con motivo del acto de Emeritierung de Rincón. También nos facilitó el manuscrito de Carlos que ilustra la portada de esta edición de la revista, y la fotografía con la cual cerramos el presente dosier. Agradecimientos también a Paola Montero y a Cristian Moreno, egresados del Departamento de Filosofía de la Universidad Nacional, por su colaboración y compromiso en la realización del homenaje del cual surge esta colaboración con la Revista Estudios de Literatura Colombiana. Sin ellos, seguramente esto no hubiera sido posible.

\section{Alejandro Sánchez Lopera y Juan David Escobar Chacón \\ University of Pittsburgh Universidad Nacional de Colombia}

